\title{
Changes in deep reef benthic community composition across a latitudinal and environmental gradient in temperate Eastern Australia
}

\author{
Lainey Clare James ${ }^{1, *}$, Martin Pierre Marzloff ${ }^{1}$, Neville Barrett ${ }^{1}$, Ariell Friedman ${ }^{2}$, \\ Craig R. Johnson ${ }^{1}$ \\ ${ }^{1}$ Institute for Marine and Antarctic Studies (IMAS), University of Tasmania, Australia IMAS/UTAS, Private Bag 129, \\ Hobart, TAS 7000, Australia \\ ${ }^{2}$ Greybits Engineering, Sydney, NSW 2029, Australia
}

\begin{abstract}
Deep reef assemblages in south-eastern Australia are poorly described, and have been surveyed by only a few studies conducted over small spatial scales. Here, we characterise the composition of deep ( 30-90 m depth) sessile invertebrate communities from sub-tropical $\left(27^{\circ} \mathrm{S}\right)$ to temperate eastern Australia $\left(43^{\circ} \mathrm{S}\right)$. We estimated the cover of 51 preselected invertebrate types from over 1700 seafloor images collected by an autonomous underwater vehicle from $>105 \mathrm{~km}$ of transects across the study region. Seafloor images were assessed using 3 alternative schemes reflecting different resolution of benthic invertebrate groupings, including the broadlevel Collaborative and Automated Tools for Analysis of Marine Imagery project ('CATAMI') classification recently developed as a generic scoring approach for seafloor imagery. Ordination using canonical analysis of principal coordinates indicated a clear latitudinal gradient in benthic community composition and, particularly when based on individual morphotypes, 3 distinct community types (sub-tropical, warm temperate and cool temperate). Changes in community structure mostly correlated with primary productivity and the temperature climatology, while local-scale variability in community composition was most related to depth. Along with the gradual shift in deep reef community composition across latitudes, region-specific sessile invertebrates might serve as useful indicators of change in these deep benthic communities under future changes in ocean climate in the region, which has been identified as a global hotspot for ocean warming. Our methodological approach has general applicability for large-scale surveying and monitoring of benthic communities using underwater imagery.
\end{abstract}

KEY WORDS: Deep marine reef - Autonomous underwater vehicle - AUV · Benthic invertebrate · Community composition · Climate change

\section{INTRODUCTION}

Habitat-forming species are essential to the structure and functioning of benthic marine communities, as they provide complex physical structure and sources of productivity that support the entire food web (Tegner \& Dayton 2000, Christie et al. 2009, Smale \& Wernberg 2013). Mesophotic reefs, often referred to in the context of tropical

*Corresponding author: laineyj@utas.edu.au coral reef communities below 30 to $150 \mathrm{~m}$ depth, are of considerable interest given their intrinsic biodiversity and ecological value (Bridge et al. 2011) and because they are poorly described. Furthermore, these deeper environments may act as refuges for species on shallower reefs under climate-driven ocean changes. While recent studies have provided detailed investigation of tropical mesophotic coral reefs (Bridge et al. 2011, 2012),

( ) The authors and IMAS 2017. Open Access under Creative Commons by Attribution Licence. Use, distribution and reproduction are unrestricted. Authors and original publication must be credited.

Publisher: Inter-Research · www.int-res.com 
studies on mesophotic reefs are limited in temperate environments.

On deep mesophotic (depth $>30 \mathrm{~m}$ ) temperate reefs, sessile invertebrates, including sponges, cnidarians, ascidians and bryozoans, dominate and contribute to the diversity, structure and functioning of benthic ecosystems (Fromont et al. 2006, Bell 2007, Schlacher et al. 2010, Schönberg \& Fromont 2012). Larger sessile invertebrates, in particular sponges, gorgonians and octocorals, provide essential structural and functional ecosystem services, including nutrient provisioning and recycling (de Goeij et al. 2013) (i.e. benthic-pelagic coupling), as well as provision of complex habitat and refuge for other organisms (Fromont et al. 2006, Bell 2007, Schlacher et al. 2010, Schönberg \& Fromont 2012).

Largely because deep-water environments are not accessible using traditional underwater sampling techniques such as visual surveys by SCUBA divers (Roberts \& Davis 1996, Pizarro et al. 2013), the distribution and ecology of deep reef communities including habitat-forming species remain poorly understood and are much less studied than their shallow coral reef and kelp-bed counterparts (Pizarro et al. 2013). Comprehensive quantitative research on deeper reef communities has only emerged relatively recently with the development of remote sampling technologies such as towed videos or autonomous underwater vehicles (AUVs), which can routinely survey benthic environments by collecting both physical measurements and photographic images of seafloor communities (Schlacher et al. 2010, Pizarro et al. 2013). Increasingly, AUVs are recognised as a valuable and effective tool to repeatedly survey and detect changes in community composition, abundance and distribution of benthic populations (Ling et al. 2016). A recent study on a reef at moderate depth (25-30 m) showed that AUV imagery detected space-time variability in the abundance of mobile macro-invertebrates in a manner comparable to traditional SCUBA diver surveys (Ling et al. 2016). While the number of studies on Australia's deeper ( $>30 \mathrm{~m}$ ) reef communities has increased over the last decade with the emergence of these novel sampling technologies (Pizarro et al. 2013), understanding of the structure and distribution of these communities remains limited. In temperate eastern Australia, despite dramatic changes in shallow reef habitat and community structure due to ongoing and rapid climate-driven ocean changes (Ling et al. 2009, Johnson et al. 2011, Marzloff et al. $2013,2016 b)$, baseline information is lacking to monitor and predict the responses of deep reef communities to large-scale ocean changes.
Although underwater imagery now provides a unique way to study and monitor deeper ocean ecosystems (Schlacher et al. 2010, Pizarro et al. 2013), accurate, consistent and detailed description of the biota from seafloor imagery remains challenging, time-consuming, and subject to human error (Althaus et al. 2015). Identification of invertebrate habitat-forming species based only on underwater imagery is limited and can rarely be performed at the species level. Recently, a standardised approach to underwater image classification was developed through the Collaborative and Automated Tools for Analysis of Marine Imagery (CATAMI) project, providing a consistent and generic means to characterise benthic substrata and associated biota from imagery (Althaus et al. 2015). While this kind of standardised approach to image classification and annotation is necessary to provide a re-usable, long-lived database of manually scored seafloor imagery (Althaus et al. 2015), the reliability of the CATAMI approach to characterise differences in benthic communities has not been tested, and the utility of its coarse characterisation remains open to question.

In this study, we used high-resolution underwater imagery taken by an AUV between 2010 and 2013 to characterise the distribution and ecology of deep $(\sim 30-90 \mathrm{~m})$ reef sessile invertebrate assemblages in eastern temperate Australia. We estimated percentage cover of 51 pre-selected benthic sessile invertebrate types across a sample of $>1700$ images taken from AUV transects totalling $>105 \mathrm{~km}$ in 7 regions along Australia's southeast coast. The aims of the work were as follows: (1) to characterise variability in deep reef community composition along a latitudinal gradient $\left(27-43^{\circ} \mathrm{S}\right)$ and identify any region-specific invertebrates; (2) to investigate the relationships between benthic invertebrate community composition and long-term environmental conditions; and (3) at a methodological level, to assess the effectiveness of both scoring of pre-selected invertebrate types based on prominent features, and using the CATAMI classification scheme for scoring marine biota in underwater imagery (compared to more detailed classification of benthic invertebrates based on distinct morphological characteristics such as colour and shape).

\section{METHODS}

We used high-resolution geo-referenced underwater images collected by the AUV 'Sirius' (operated through the Australian Integrated Marine Observing 


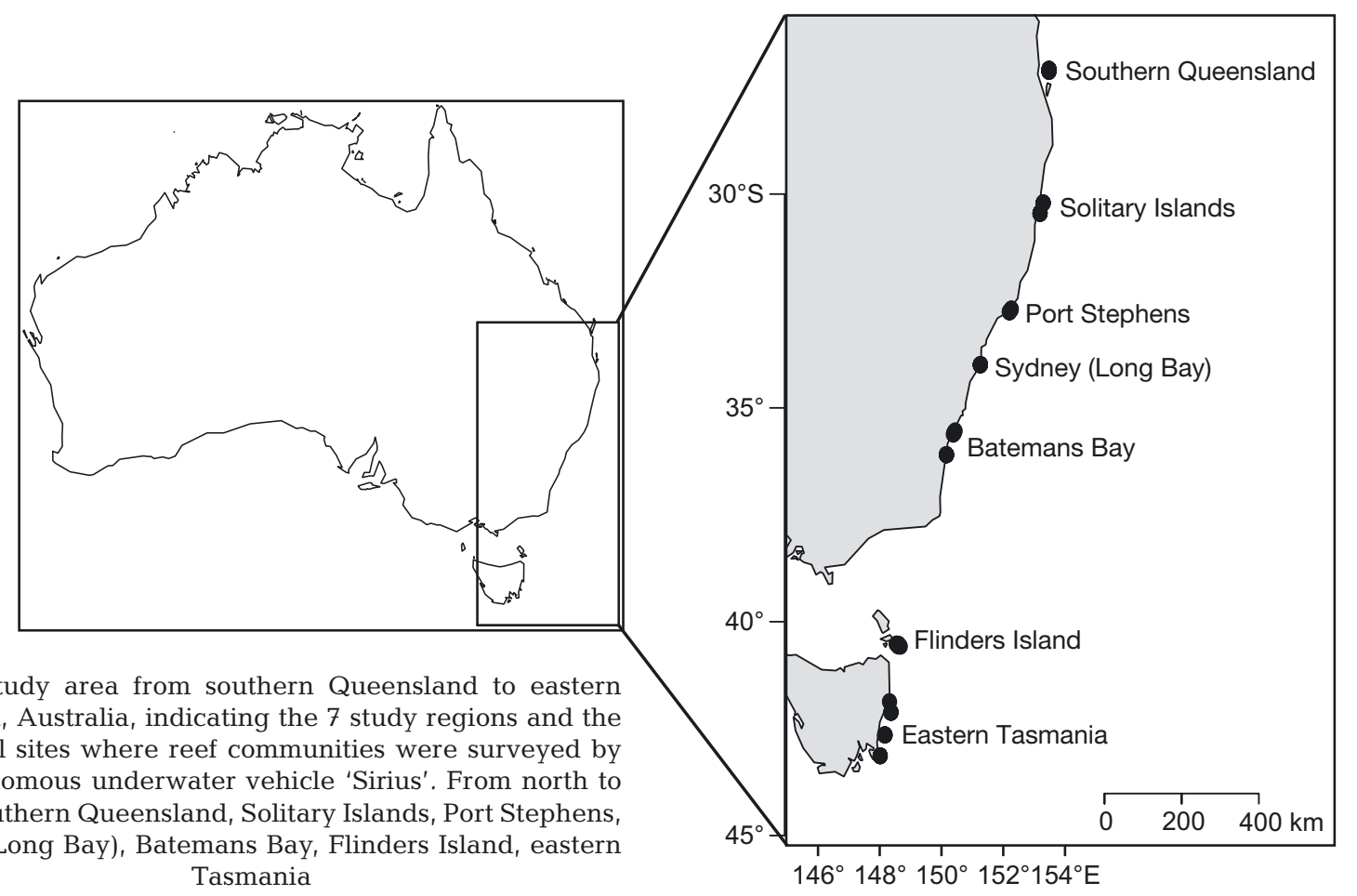

Fig. 1. Study area from southern Queensland to eastern Tasmania, Australia, indicating the 7 study regions and the individual sites where reef communities were surveyed by the autonomous underwater vehicle 'Sirius'. From north to south: southern Queensland, Solitary Islands, Port Stephens, Sydney (Long Bay), Batemans Bay, Flinders Island, eastern Tasmania

transects covering 500 to $1000 \mathrm{~m}$ and (2) smaller-scale System [IMOS] by the Australian Centre for Field Robotics, University of Sydney) to survey the structure of sub-tidal sessile benthic invertebrate assemblages on rocky reefs at depths greater than $30 \mathrm{~m}$ along the southeast coast of Australia. This AUV navigates $\sim 2 \mathrm{~m}$ above the seafloor at $\sim 0.5-1 \mathrm{~m} \mathrm{~s}^{-1}$, photographing, on average, an area of the seafloor approximately $2.1 \mathrm{~m}^{2}$ every second (see Williams et al. 2012). All data collected by the AUV are freely accessible through the IMOS Ocean Portal (http:// imos.aodn.org.au) and also through Squidle (http:// squidle.acfr.usyd.edu.au).

\section{Study area and survey design}

We used all latest available IMOS AUV surveys conducted at depths greater than $30 \mathrm{~m}$ between 2010 and 2013 from southeast Queensland $\left(27^{\circ} \mathrm{S}\right)$ to southeast Tasmania $\left(43^{\circ} \mathrm{S}\right)$. We clustered the 12 AUV sample sites available across eastern temperate Australia into 7 broad regions based on latitude (Fig. 1). The seascape at all sites was characterised by reef structures interspersed with (occasionally extensive) sand patches. The range of reef structure comprised hard consolidated substratum and unconsolidated sand and biogenic gravel veneer over bedrock. The IMOS benthic monitoring programme uses a nested hierarchical sampling design, in which the AUV is programmed to run both (1) broad-scale, sparse grid complete coverage of $25 \times 25 \mathrm{~m}$ patches. All available AUV tracks within each region were sampled in the current study (see Table S1 in the Supplement at www.int-res.com/articles/suppl/m565p035_supp.pdf).

\section{Benthic invertebrate selection and classification}

We first conducted a pilot study to define a selection of sessile benthic invertebrate types for targeted scoring of AUV images. After examining random subsets of images across all survey sites, we selected invertebrate types with characteristic features (e.g. of shape, colour and size) enabling rapid and unambiguous image annotation. At the end of this process, 51 different sessile benthic invertebrate types were selected for quantitative scoring, including 2 ascidians, 4 bryozoans, 7 cnidarians and 38 sponges (see example specimens in Fig. $2 \mathrm{~A}_{i}$ a full list and details of invertebrate types are provided in Table S2 in the Supplement).

Due to their high phenotypic plasticity, identifying benthic invertebrates, particularly sponges, to species level from underwater imagery is challenging without additional extractive sampling for more thorough taxonomic and genetic studies (Althaus et al. 2015). Therefore, invertebrate types were classified using the CATAMI classification scheme for scoring marine biota and substrata in underwater imagery (Althaus et al. 2015). In CATAMI, sponges are classified based 


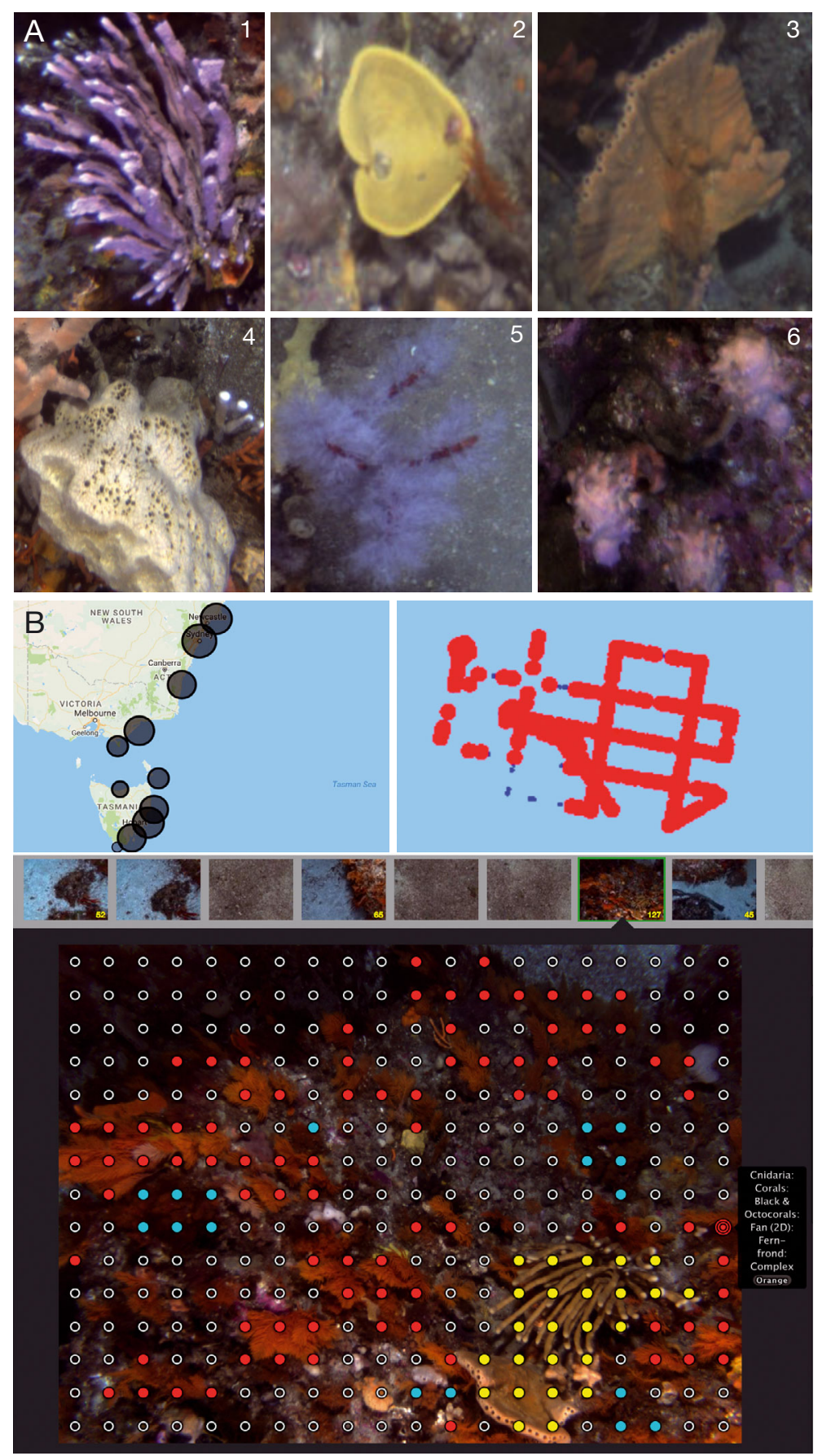

Fig. 2. (A) Example invertebrates, taken from the subset of the 51 morphotypes selected for scoring given their characteristic features (i.e. large size, strong features and obvious colours): (1) purple branching sponge, (2) yellow cup sponge, (3) orange laminar sponge, (4) white (shapeless) massive sponge, (5) blue hydroid blackcoral, (6) purple solitary ascidian. See Table S2 in the Supplement at www.int-res.com/articles/suppl/m565p035_supp.pdf for a full list of scored invertebrate types, with corresponding pictures. (B) Example of the 'Squidle' online interface for sub-sampling (top panels) and annotation (bottom) of autonomous underwater vehicle imagery. Black circles correspond to available AUV campaigns (top left), from which transects and images within transects can be sub-sampled based on user-defined criteria such as image depth (red dots represent selected images; top right panel). The bottom panel illustrates how each selected image can be directly annotated online using the CATAMI classification scheme (each group appear as a different colour) as well as custom classifiers on growth forms, while ascidians, bryozoans and cnidarians are lumped into broad classes (Althaus et al. 2015). To test the limitations of the CATAMI classification scheme relative to more detailed annotation approaches, we also recorded specific colours and shape characteristics in addition to the CATAMI identifier. We used 3 alternative invertebrate classification schemes of increasing resolution: (1) 'CATAMI', (2) 'Group' (CATAMI classification with an additional [single] colour or shape classifier) and (3) individual 'Morphotype' (CATAMI classification with both a colour and a shape classifier; see Table S2 in the Supplement for details).

\section{AUV image sampling}

Sub-sampling and annotation of images was done using Squidle. Squidle is a webbased interface for the management, exploration and analysis of seafloor imagery that has been developed by the Australian Centre for Field Robotics at the University of Sydney (see Fig. 2B; http://squidle.acfr. usyd.edu.au). The sub-sampling of images from all available IMOS AUV imagery was done using the query tools available through the Squidle web interface and followed a 3-step process: image datasets were created at each site by selecting images from the most recent available surveys (as of January 2014), at depths $>30 \mathrm{~m}$ and where the AUV was cruising at a stable altitude between 1.5 and $2.5 \mathrm{~m}$ above the seafloor. Next, a random subset of 1000 images was drawn from each site; within each subset, a minimum of 100 good-quality (i.e. well-illuminated and in focus) images that had $>50 \%$ reef were scored. Across the 7 regions, a total of 1882 images were selected including 356 from southern Queensland, 348 from the Solitary Islands, 180 from Port Stephens, 188 from Sydney (Long Bay), 284 from Batemans Bay, 129 from Flinders Island and 397 from eastern Tasmania. These images were then annotated using Squidle's online annotation tool, which provides access to an extended version of the CATAMI classification scheme, as well as 
the provision to add the additional colour and shape modifiers mentioned above. Note that due to the deep depths (30-90 m), largely open and exposed nature of the sites and total transect length extending over $105 \mathrm{~km}$, diver based ground-truthing of AUV imagery was considered impractical and beyond the scope of the present study.

\section{Image scoring and methodology}

A 300-point regular grid (20 columns by 15 rows) was overlaid over each image (see Fig. 2B). To estimate percentage covers, each grid point that covered a targeted invertebrate type was labelled with the relevant CATAMI identifier, shape and colour (see Fig. 2B and Table S2 in the Supplement).

\section{Environmental data}

We extracted a range of metrics to characterise the mean environmental conditions associated with each of the scored images based on their geographic coordinates (i.e. longitude, latitude). After filtering out highly correlated variables $(|r|>0.75)$, we retained 15 environmental predictors in the distance-based analyses relating the variability in community structure with the physical environment (note: the numbering that follows simply delineates the 15 predictors and does not match the numbering assigned in the figures and tables):

- (1) Depth information was available in situ from the IMOS AUV

- A temperature climatology was derived from high-resolution $\left(0.1^{\circ}\right.$ latitude and longitude) daily sea surface temperature (SST) fields available on the continental shelf of Australia for the period of 1993-2008 from Oliver \& Holbrook (2014). Assuming consistent regular vertical mixing on the continental shelf, we used daily estimates of SST as a proxy for bottom temperature to derive the following 3 variables at each sample site: (2) mean temperature $\left({ }^{\circ} \mathrm{C}\right)$; (3) seasonal temperature range (amplitude of the fitted seasonal cycle; ${ }^{\circ} \mathrm{C}$ ); and, to characterise high-frequency variability in temperature, the (4) standard deviation in daily temperature estimates after filtering out the seasonal cycle. Note that in this work we inspected the correlation between SST and bottom temperature on the continental shelf of eastern Australia based on available data from IMOS moorings, temperature sensors on the AUV and benthic temperature loggers deployed around Tasmania (C. Mundy unpublished data). We found that some local stratification can occur between surface and bottom water parcels at fine spatio-temporal scales (e.g. seasonal stratification occurs in some places), but that overall SST constitutes a valid proxy for bottom temperature on the continental shelf over large scales and smoothed over seasonal signals. Since we used a long-term climatology of SST across a large latitudinal gradient, we are confident in the robustness of these data in the context of our study. Smale \& Wernberg (2009) also concluded that SST constitutes a valid proxy to characterise long-term climatology of bottom temperature on the continental shelf over large scales (>100 km)

- Shear stress near the seafloor was estimated using hourly outputs from the GEOMACS model available at a 0.1 latitude and longitude resolution over the period March 1997 to February 2008 inclusive (Hemer 2006). We considered 3 alternative metrics: (5) mean shear stress (in Pa), (6) excess shear stress $(\%)$, i.e. the proportion of hours when shear stress is above the critical value of 0.4 Pa (Long et al. 1997), and (7) ratio shear stress (an index between 0 and 1), calculated as the ratio between extreme shear stress (>0.4 Pa) integrated over time and overall shear stress integrated over time

- Level of surface primary productivity, which was indirectly estimated by using (8) mean chlorophyll a (chl a) estimates from SeaWiFs as a proxy $\left(\mathrm{ml} \mathrm{l}^{-1}\right.$; $4 \mathrm{~km}$ resolution; monthly for the period 1997-2010; Barnes et al. 2001, Eplee et al. 2001)

- Long-term chemical ocean properties were derived from weekly estimates available at $1 / 8^{\circ}$ resolution as part of the 2008 CSIRO Atlas of Regional Seas (CARS) based on the World Ocean Database 2005 (WOD05 update from July 2008) (Dunn \& Ridgway 2002, Ridgway et al. 2002). Specifically, estimates of the (9) mean and (10) seasonal range were extracted for oxygen (in ml l-1) and the (11) mean and (12) seasonal range for silicate (in mol 1-1) concentration, while the (13) seasonal range was obtained for phosphate (in mol 1-1) (mean phosphate was not used as it was highly correlated $(|r|>0.75)$ with oxygen, as determined using a draughtsman plot)

- Seafloor topography (i.e. (14) relief and (15) slope) was estimated based on the bathymetry dataset available from Geoscience Australia at $250 \mathrm{~m}$ resolution (Huang 2013).

\section{Data processing and statistical analysis}

To study the gradient in deep reef community composition across temperate latitudes, all available 

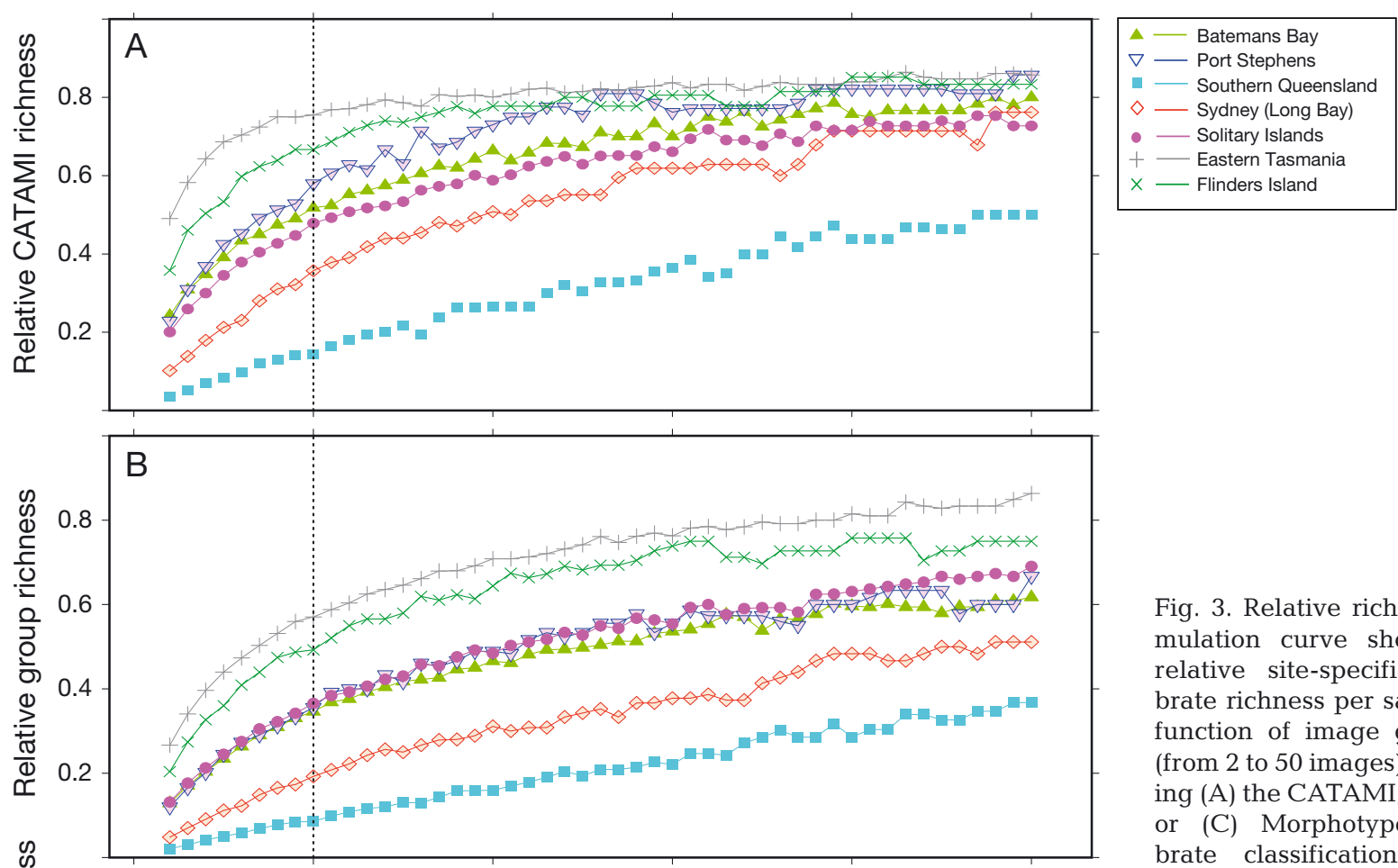

Fig. 3. Relative richness accumulation curve showing the relative site-specific invertebrate richness per sample as a function of image group size (from 2 to 50 images), when using (A) the CATAMI, (B) Group or (C) Morphotype invertebrate classification schemes (see 'Methods' for details of each scheme). Percentage covers of each type were averaged across a group of $\mathrm{n}$ (between 2 and 50) adjacent images along each transect ( $x$-axis), and mean relative richness per sample group (y-axis) was estimated as a proportion of the total richness surveyed in the region. All statistical analyses were based on groups of 10 images (dotted vertical line), which overall captured $\sim 40 \%$ of the CATAMI group diversity surveyed in each region

samples were grouped into 7 regions: southern Queensland, Solitary Islands, Port Stephens, Sydney (Long Bay), Batemans Bay, Flinders Island and eastern Tasmania (from north to south, respectively), based on latitude (Fig. 1).

Image grouping along AUV transects to analyse ecologically meaningful spatial scales

For our community-based analyses to be ecologically meaningful and also to meet the data handling capacity of the PRIMER software, we aggregated consecutive, non-overlapping images that were scored along AUV transects to create sampling units that are sufficiently large to represent local commu- nity composition. To define an adequate size of sampling unit, we inspected the effects of increasing the number of photos that constitute a sampling unit (from 2 to 50 images per unit) on the mean proportion of organisms in each region that are detected within a single sampling unit (Fig. 3). Morphospecies diversity increases in 2 phases as a function of the number of images defining a sampling unit (Fig. 3): (1) from 2 up to 10 images per sampling unit, the relative diversity per sample increases steeply (most noticeably using the coarsest CATAMI classification; Fig. 3A); (2) from $\sim 10$ to 50 images per unit, the increase in relative diversity per sample is more marginal as the curve reaches a plateau (Fig. 3). With more detailed classifications, the overall number of groups considered increases from 13 CATAMI groups (shown in 
Table 1. Summary of permutational multivariate ANOVA for each classification level (see 'Methods' for details of each classification), testing for differences in sessile benthic invertebrate community composition between regions. All tests based on Bray-Curtis similarity matrix of square-root transformed percentage cover data

\begin{tabular}{|lcccc|}
\hline Classification & df & MS & $F$ & p(perm) \\
\hline CATAMI & 6 & 26985 & 23.033 & 0.001 \\
Group & 6 & 32668 & 17.287 & 0.001 \\
Morphotype & 6 & 34724 & 15.614 & 0.001 \\
\hline
\end{tabular}

Fig. 3A) to 29 'benthic groups' (Fig. 3B) and 51 morphospecies (Fig. 3C), and the relative diversity per sample increases more slowly with increasing number of images per sample. Not surprisingly, the accumulation curve of diversity per sample as a proportion of regional diversity reaches an asymptote faster when we consider the 13 broad CATAMI groups rather than the 51 morphospecies. Based on the position of the plateau in these diversity accumulation curves (see vertical line in Fig. 3), we defined sampling units as an aggregation of 10 closest images along each transect. Thus, on average each sampling unit captures $\sim 40 \%$ of the CATAMI group richness and $\sim 25 \%$ of the morphotype richness surveyed within any one region (Fig. 3), except in the southern Queensland and Sydney regions, where target invertebrates were absent on $\sim 93$ and $66 \%$ of the scored images, respectively. The minimum sample size for any one region was 10 sampling units (where each unit is an aggregation of 10 photos).

\section{Variation in benthic morphotype assemblage composition}

For each of the classification levels (i.e. CATAMI, Group, Morphotype), we computed similarity matrices across all samples based on Bray-Curtis distances of square-root transformed percentage cover data (to reduce the influence of abundant invertebrate types relative to rarer ones).

Differences in sessile benthic invertebrate community composition between samples were first visualised with non-metric multidimensional scaling (nMDS) (see Fig. 4) (Clarke et al. 2006), then with constrained canonical analysis of principal coordinates (CAP) using each of the 7 survey regions (see Fig. 5) and 3 broad community types (i.e. subtropical, warm and cold temperate; see Fig. 5) as grouping factors. In the CAP, invertebrate types that most contributed to the differences in community composition between regions (Spearman's correlation $\geq 0.04$ with the principal discriminant plane of the CAP) (Anderson \& Willis 2003) are shown as vectors (see Fig. 5). Finally, a permutational multivariate ANOVA (PERMANOVA) based on a Bray-Curtis similarity matrix of square-root transformed percentage cover data was used to test for significant differences in multivariate community composition between regions.

Relationship between mean environmental conditions and benthic invertebrate composition

All 15 environmental predictors (depth, oxygen [mean and seasonal range], phosphate [seasonal range], silicate [mean and seasonal range], chl a [mean], average relief [bathymetry], slope [bathymetry], sheer stress [excess, mean and ratio] and SST [mean, seasonal range and the standard deviation of the seasonal range]), were normalised due to the different measurement units. The relationship between changes in community composition and mean environmental conditions was analysed using distance-based linear model (DISTLM) and distance-based redundancy analysis (dbRDA) (Legendre \& Anderson 1999). For each classification level, 4 DISTLMs using alternative selection criteria (Akaike's information criterion, Bayesian information criterion [BIC]) and procedures (Step-wise, Best) were run to determine the most parsimonious model (see Table S3 in the Supplement). Ultimately we used the BIC selection criterion with step-wise selection procedure to provide parsimonious solutions (see Table S3). All multivariate analyses were undertaken using the PRIMER-6 statistical software with the PERMANOVA+ add on (Anderson et al. 2008).

\section{RESULTS}

\section{Community-based analyses}

Overall, differences in invertebrate community composition were highly significant between the 7 areas irrespective of the level of classification of invertebrate groups $(p<0.01$ in all cases; Table 1$)$. The nMDS reflects a gradual change in community composition along the north-south latitudinal gradient (Fig. 4), although with increasing resolution of invertebrate classification, there is clearly a trend for Tas- 


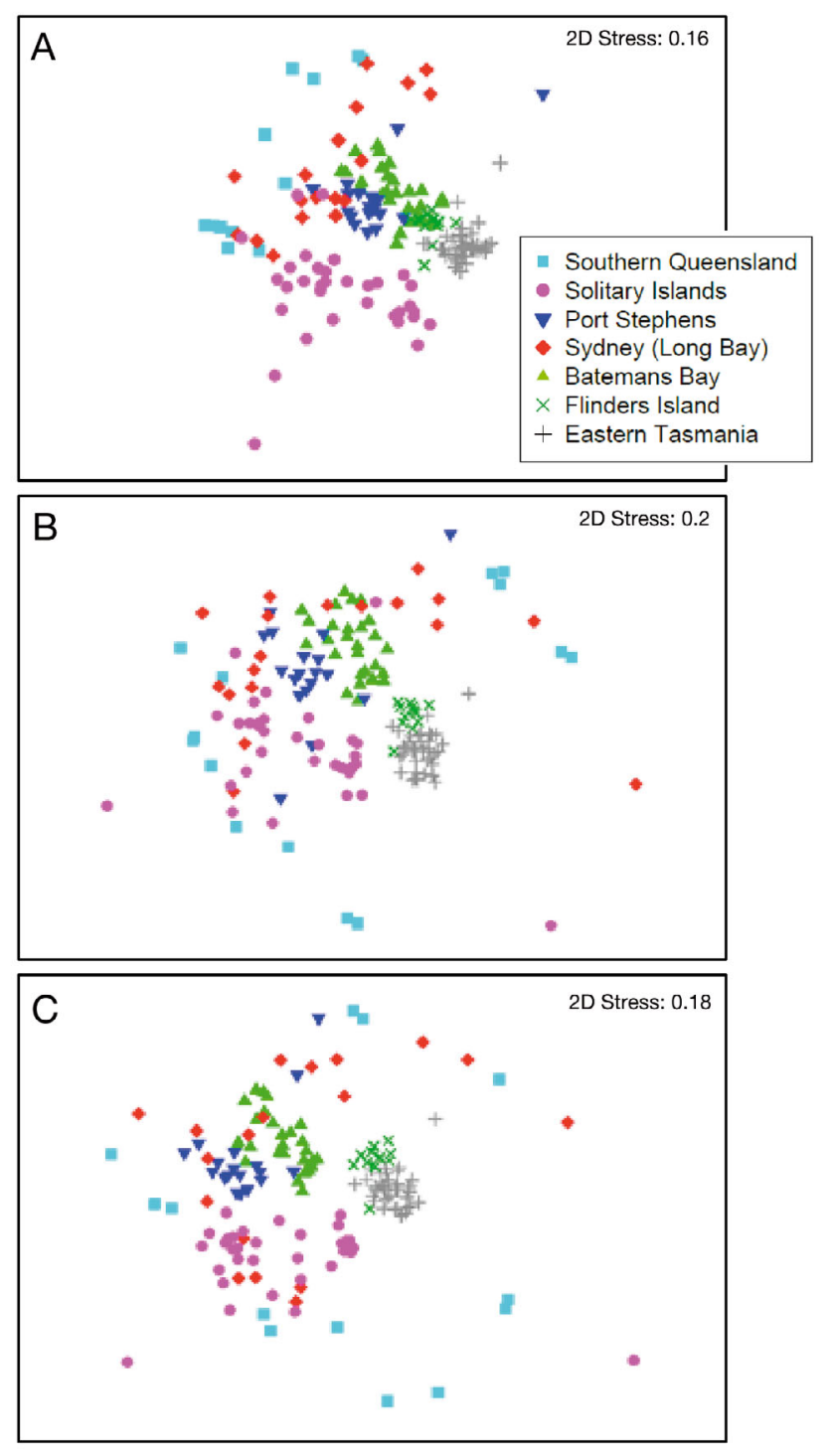

Fig. 4. Two-dimensional multidimensional scaling of variability in benthic community composition across the 7 survey regions (symbolised by different symbols and colours), based on Bray-Curtis similarity in invertebrate percentage covers using the (A) CATAMI, (B) Group and (C) Morphotype benthic invertebrate classifications (see 'Methods' for details of each classification)

manian areas (Flinders Island, eastern Tasmania), southern (Batemans Bay) and central (Port Stephens) New South Wales, and sub-tropical reefs at the Solitary Islands to stand out as distinct regional clusters (cf. Fig. 4). Samples from southern Queensland and Sydney (Long Bay), both characterised by a relatively depauperate fauna, are spread across the nMDS space, revealing high variability among samples within these areas. Note that these were the only 2 areas where differences in community composition
Table 2. Summary of pair-wise comparisons (permutational multivariate ANOVA) of community composition among regions at the CATAMI, Group and Morphotype levels of classification (see 'Methods' for details of each classification). All tests are based on Bray-Curtis similarity matrix of square-root transformed percentage cover data. BB: Batemans Bay, PS: Port Stephens, SQ: southern Queensland, SYD: Sydney, SS: Solitary Islands, SET: southeast Tasmania, FI: Flinders Island

\begin{tabular}{|lccc|}
\hline Comparison & $\begin{array}{c}\text { CATAMI } \\
\text { p(perm) }\end{array}$ & $\begin{array}{c}\text { Group } \\
\text { p(perm) }\end{array}$ & $\begin{array}{c}\text { Morphotype } \\
\text { p(perm) }\end{array}$ \\
\hline BB vs. PS & 0.001 & 0.001 & 0.001 \\
BB vs. SQ & 0.001 & 0.001 & 0.001 \\
BB vs. SYD & 0.001 & 0.001 & 0.001 \\
BB vs. SS & 0.001 & 0.001 & 0.001 \\
BB vs. SET & 0.001 & 0.001 & 0.001 \\
BB vs. FI & 0.001 & 0.001 & 0.001 \\
PS vs. SQ & 0.001 & 0.001 & 0.001 \\
PS vs. SYD & 0.004 & 0.001 & 0.001 \\
PS vs. SS & 0.001 & 0.001 & 0.001 \\
PS vs. SET & 0.001 & 0.001 & 0.001 \\
PS vs. FI & 0.001 & 0.001 & 0.001 \\
SQ vs. SYD & 0.067 & 0.025 & 0.006 \\
SQ vs. SS & 0.001 & 0.001 & 0.001 \\
SQ vs. SET & 0.001 & 0.001 & 0.001 \\
SQ vs. FI & 0.001 & 0.001 & 0.001 \\
SYD vs. SS & 0.001 & 0.001 & 0.001 \\
SYD vs. SET & 0.001 & 0.001 & 0.001 \\
SYD vs. FI & 0.001 & 0.001 & 0.001 \\
SS vs. SET & 0.001 & 0.001 & 0.001 \\
SS vs. FI & 0.001 & 0.001 & 0.001 \\
SET vs. FI & 0.001 & 0.001 & 0.001 \\
\hline
\end{tabular}

were not statistically significant when using the lowresolution CATAMI classification $(\mathrm{p}=0.067$; pairwise PERMANOVA, Table 2), which most likely reflects the high number of shared absences.

Consistent with the nMDS, the CAP also indicates 3 well-defined community types (Fig. 5): (1) 'sub-tropi$\mathrm{Cal}^{\prime}$, corresponding to samples from southern Queensland and the Solitary Islands, (2) 'warm temperate', corresponding to samples from Port Stephens and Batemans Bay, and (3) 'cool temperate', corresponding to samples from Flinders Island and eastern Tasmania (Fig. 5). At all 3 classification levels, the first CAP axis discriminates between the Tasmanian and mainland regions. Community composition at the Solitary Islands also appears distinct, clustered to the bottom left of the plot. As the classification becomes more detailed (i.e. moving from CATAMI to Group to Morphotype level; Fig. 5A-C, respectively), the warm temperate community (Port Stephens and Batemans Bay) and sub-tropical community (southern Queensland and Solitary Islands) appear as 2 distinct groups along the second CAP axis. As with the nMDS, samples from Sydney (Long Bay) are spread 

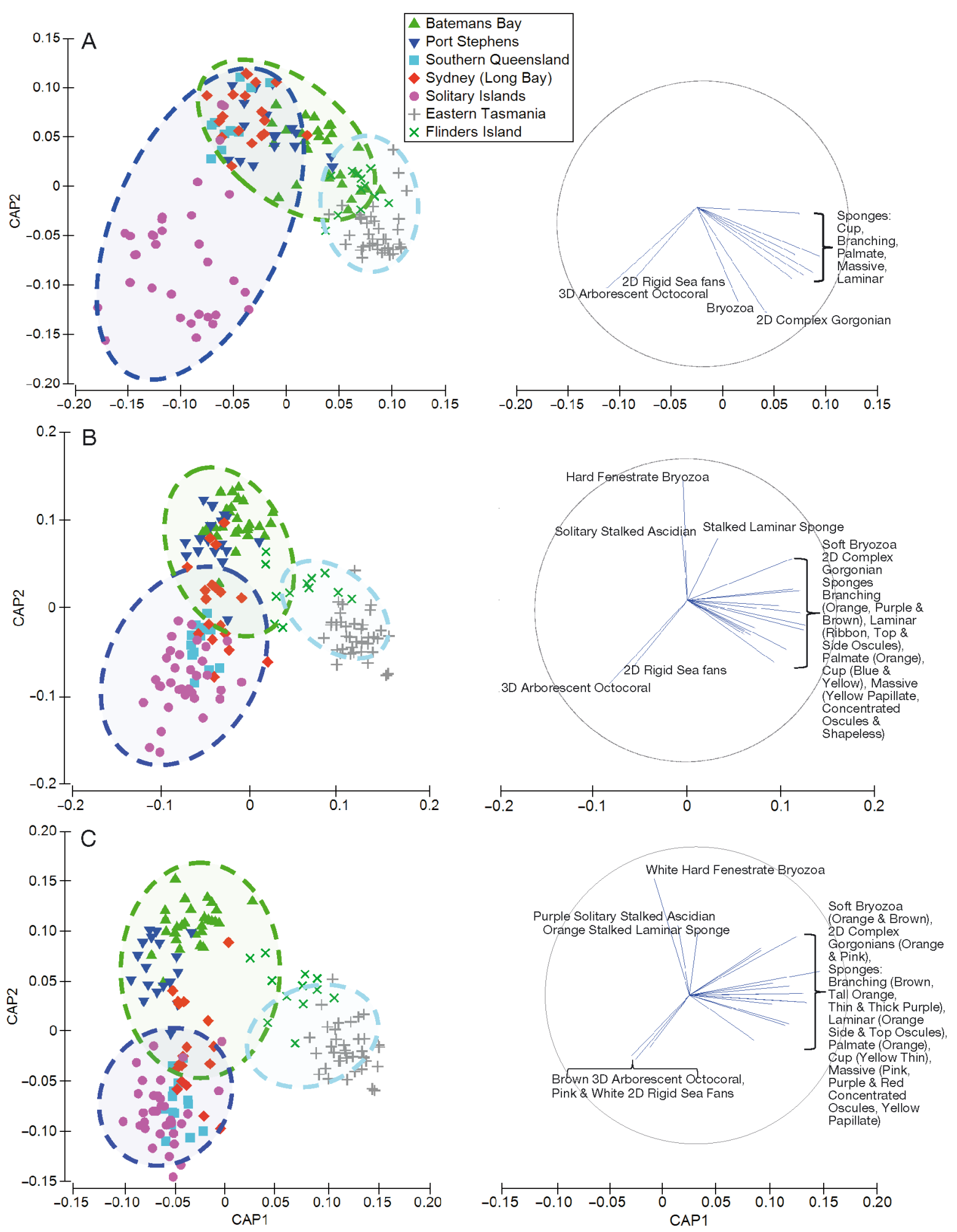

Fig. 5. Canonical analysis of principal coordinates (CAP) ordination of sampled benthic community composition using each of the 7 survey regions (see Fig. 1), overlaid with CAP ordination of broad-scale community types (expressed as ellipses) (i.e. subtropical $=$ dark blue, warm temperate $=$ green, cool temperate $=$ light blue). Analysis is based on Bray-Curtis similarity matrix of square-root transformed percentage cover data. Vector overlay to right-hand side of each plot indicates the strength and direction of correlation with invertebrate types using (A) CATAMI, (B) Group and (C) Morphotype classification (see 'Methods' for details of each classification). Vectors are only shown for Spearman's correlation $\geq 0.4$ 
Table 3. Results of CATAMI level (see 'Methods' for details of the CATAMI classification) distance-based linear model relating changes in benthic sessile invertebrate community composition with environmental predictors. Marginal tests identify the explanatory power of each predictor in isolation while the BEST solution identifies the combination of predictors best capturing the observed variability in community composition using the Bayesian information criterion (BIC) selection criterion. Prop.: proportion of variation explained by each predictor or combination of predictors; RSS: residual sums of squares

\begin{tabular}{|c|c|c|c|c|}
\hline $\begin{array}{l}\text { Marginal tests } \\
\text { Variable }\end{array}$ & SS(trace) & Pseudo- $F$ & $\mathrm{p}$ & Prop. \\
\hline (1) Depth & 38271 & 20.013 & 0.0001 & 0.1118 \\
\hline (2) Oxygen (mean) & 13949 & 6.7543 & 0.0002 & $4.0749 \times 10^{-2}$ \\
\hline (3) Oxygen (seasonal range) & 26294 & 13.229 & 0.0001 & $7.681 \times 10^{-2}$ \\
\hline (4) Phosphate (seasonal range) & 18488 & 9.0772 & 0.0001 & $5.4006 \times 10^{-2}$ \\
\hline (5) Silicate (mean) & 4840.5 & 2.2805 & 0.039 & $1.414 \times 10^{-2}$ \\
\hline (6) Silicate (seasonal range) & 17981 & 8.8147 & 0.0001 & $5.2526 \times 10^{-2}$ \\
\hline (7) Chlorophyll a (mean) & 17268 & 8.4466 & 0.0001 & $5.0444 \times 10^{-2}$ \\
\hline (8) Relief (bathymetry) average & 10224 & 4.8949 & 0.0006 & $2.9866 \times 10^{-2}$ \\
\hline (9) Slope (bathymetry) & 7151.9 & 3.3927 & 0.0043 & $2.0892 \times 10^{-2}$ \\
\hline (10) Shear stress (excess) & 5148.3 & 2.4277 & 0.0308 & $1.5039 \times 10^{-2}$ \\
\hline (11) Shear stress (mean) & 33821 & 17.431 & 0.0001 & $9.8797 \times 10^{-2}$ \\
\hline (12) Shear stress (ratio) & 30496 & 15.55 & 0.0001 & $8.9084 \times 10^{-2}$ \\
\hline (13) Sea surface temperature (mean) & 85046 & 52.559 & 0.0001 & 0.24843 \\
\hline (14) Sea surface temperature (seasonal range) & 12710 & 6.1309 & 0.0001 & $3.7128 \times 10^{-2}$ \\
\hline $\begin{array}{l}\text { (15) Standard deviation of sea surface } \\
\text { temperature (seasonal range) }\end{array}$ & 11024 & 5.2908 & 0.0001 & $3.2204 \times 10^{-2}$ \\
\hline \multicolumn{5}{|l|}{ BEST solution } \\
\hline $\mathrm{BIC}$ & $\mathrm{R}^{2}$ & RSS & No. variables & Selections \\
\hline 1162.9 & 0.48311 & $1.7695 \times 10^{-5}$ & 6 & $1,7,12-15$ \\
\hline
\end{tabular}

across the second CAP axis. The results of the CAP using the 3 broad community types (i.e. sub-tropical, warm temperate and cool temperate) as grouping factors highlight the well-defined distinction between these 3 sessile invertebrate communities (Fig. 5).

The vector plots projected onto the first 2 axes of the CAPs (Fig. 5) reveal characteristic region-specific invertebrate groups. They indicate that abundances of large erect (branching, laminar and palmate), massive and cup sponges, soft bryozoans and soft gorgonians, and various species-morphs of these invertebrate types, contribute most to the distinctiveness of cool temperate reef communities (Flinders Island and eastern Tasmania). Sea fans and branching octocorals are characteristic features of sub-tropical communities (Solitary Islands and southern Queensland), while the stalked solitary ascidian and the fenestrate bryozoan mostly occur in warm temperate communities (Port Stephens and Batemans Bay).

\section{Relationship between environmental conditions and benthic invertebrate composition}

Across all 3 invertebrate classification levels and alternative model fitting procedures, 6 environmental variables out of 15 were consistently selected in
DISTLM as significantly correlated with variability in community composition. These environmental variables include depth, mean chl $a$, shear stress (ratio), mean SST, seasonal range in mean SST and day-today variability in mean SST (Tables 3 to 5).

The associated dbRDA ordinations (in which the first 2 axes capture 78.5, 72.1 and $70.4 \%$ of the fitted variation in community composition between regions at the CATAMI, Group and Morphotype classification levels, respectively; Fig. 6), as with the CAP ordination, shows clear differences in community structure along the latitudinal gradient. The vector overlays, which indicate the direction and strength of correlation of each of the environmental predictors with the first 2 dbRDA axes, reflect that mean SST $(24.8,17.9,16.3 \%)$, depth $(11.2,9.8,10.2 \%)$, shear stress $(8.9,7.9,5.0 \%)$ and mean chl a $(5.0,4.7,5.1 \%)$ explain most of the observed variability in community structure (for CATAMI, Group and Morphotype levels of classification, respectively; Tables 3 to 5). Large-scale variation in community composition along the latitudinal gradient from south to north positively correlates with mean SST, from left to right along the first PC axis (Fig. 6). Indeed, mean SST and, to a lesser extent, shear stress ratio and mean primary productivity ( $\mathrm{chl}$ a) correlate with differences in community composition across regions. Mean 
Table 4. As in Table 3, for Group level (see 'Methods' for details of the Group classification) distance-based linear model

\begin{tabular}{|c|c|c|c|c|}
\hline $\begin{array}{l}\text { Marginal tests } \\
\text { Variable }\end{array}$ & $\mathrm{SS}($ trace) & Pseudo- $F$ & $\mathrm{p}$ & Prop. \\
\hline (1) Depth & 47026 & 17.347 & 0.0001 & $9.8366 \times 10^{-2}$ \\
\hline (2) Oxygen (mean) & 15721 & 5.4063 & 0.0001 & $3.2884 \times 10^{-2}$ \\
\hline (3) Oxygen (seasonal range) & 22596 & 7.888 & 0.0001 & $4.7265 \times 10^{-2}$ \\
\hline (4) Phosphate (seasonal range) & 17226 & 5.9434 & 0.0001 & $3.6033 \times 10^{-2}$ \\
\hline (5) Silicate (mean) & 8792.5 & 2.979 & 0.0029 & $1.8391 \times 10^{-2}$ \\
\hline (6) Silicate (seasonal range) & 14514 & 4.9782 & 0.0001 & $3.0359 \times 10^{-2}$ \\
\hline (7) Chlorophyll a (mean) & 22793 & 7.9601 & 0.0001 & $4.7677 \times 10^{-2}$ \\
\hline (8) Relief (bathymetry) average & 15719 & 5.4055 & 0.0001 & $3.2879 \times 10^{-2}$ \\
\hline (9) Slope (bathymetry) & 11622 & 3.9616 & 0.0001 & $2.431 \times 10^{-2}$ \\
\hline (10) Shear stress (excess) & 8574.8 & 2.9039 & 0.0033 & $1.7936 \times 10^{-2}$ \\
\hline (11) Shear stress (mean) & 46030 & 16.94 & 0.0001 & $9.6283 \times 10^{-2}$ \\
\hline (12) Shear stress (ratio) & 38204 & 13.81 & 0.0001 & $7.9913 \times 10^{-2}$ \\
\hline (13) Sea surface temperature (mean) & 82644 & 33.231 & 0.0001 & 0.17287 \\
\hline (14) Sea surface temperature (seasonal range) & 16550 & 5.7017 & 0.0001 & $3.4619 \times 10^{-2}$ \\
\hline $\begin{array}{l}\text { (15) Standard deviation of sea surface } \\
\text { temperature (seasonal range) }\end{array}$ & 18827 & 6.5184 & 0.0001 & $3.9382 \times 10^{-2}$ \\
\hline \multicolumn{5}{|l|}{ BEST solution } \\
\hline $\mathrm{BIC}$ & $\mathrm{R}^{2}$ & RSS & No. variables & Selections \\
\hline 1240.4 & 0.40119 & $2.8628 \times 10^{-5}$ & 6 & $1,7,12-15$ \\
\hline
\end{tabular}

Table 5. As in Table 3, for Morphotype level (see 'Methods' for details of the Morphotype classification) distance-based linear model

\begin{tabular}{|c|c|c|c|c|}
\hline $\begin{array}{l}\text { Marginal tests } \\
\text { Variable }\end{array}$ & SS(trace) & Pseudo- $F$ & $\mathrm{p}$ & Prop. \\
\hline (1) Depth & 56141 & 18.047 & 0.0001 & 0.10193 \\
\hline (2) Oxygen (mean) & 19777 & 5.9221 & 0.0001 & $3.5908 \times 10^{-2}$ \\
\hline (3) Oxygen (seasonal range) & 23271 & 7.0143 & 0.0001 & $4.2251 \times 10^{-2}$ \\
\hline (4) Phosphate (seasonal range) & 17281 & 5.1503 & 0.0001 & $3.1376 \times 10^{-2}$ \\
\hline (5) Silicate (mean) & 9582.2 & 2.8153 & 0.0039 & $1.7398 \times 10^{-2}$ \\
\hline (6) Silicate (seasonal range) & 12977 & 3.8368 & 0.0002 & $2.3562 \times 10^{-2}$ \\
\hline (7) Chlorophyll a (mean) & 28013 & 8.5202 & 0.0001 & $5.0861 \times 10^{-2}$ \\
\hline (8) Relief (bathymetry) average & 18611 & 5.5606 & 0.0001 & $3.3791 \times 10^{-2}$ \\
\hline (9) Slope (bathymetry) & 12020 & 3.5475 & 0.0003 & $2.1825 \times 10^{-2}$ \\
\hline (10) Shear stress (excess) & 7514 & 2.1992 & 0.0146 & $1.3643 \times 10^{-2}$ \\
\hline (11) Shear stress (mean) & 54387 & 17.421 & 0.0001 & $9.8747 \times 10^{-2}$ \\
\hline (12) Shear stress (ratio) & 42645 & 13.344 & 0.0001 & $7.7429 \times 10^{-2}$ \\
\hline (13) Sea surface temperature (mean) & 89970 & 31.044 & 0.0001 & 0.16335 \\
\hline (14) Sea surface temperature (seasonal range) & 25530 & 7.7283 & 0.0001 & $4.6353 \times 10^{-2}$ \\
\hline $\begin{array}{l}\text { (15) Standard deviation of sea surface } \\
\text { temperature (seasonal range) }\end{array}$ & 21739 & 6.5338 & 0.0001 & $3.9471 \times 10^{-2}$ \\
\hline \multicolumn{5}{|l|}{ BEST solution } \\
\hline $\mathrm{BIC}$ & $\mathrm{R}^{2}$ & RSS & No. variables & Selections \\
\hline 1266.8 & 0.38752 & $3.3733 \times 10^{-5}$ & 6 & $1,7,12-15$ \\
\hline
\end{tabular}

chl a discriminates between more productive Tasmanian sites and those on the mainland. Depth is largely correlated with intra-region variability at each classification level. A large proportion of the variability in community composition remains unexplained by the principal plane of the dbRDA, which only captures about one-third of the total variation in community structure regardless of the classification schemes (CATAMI, Group or Morphotype), suggesting that these communities are influenced by environmental variables or ecological processes that we have not considered. 

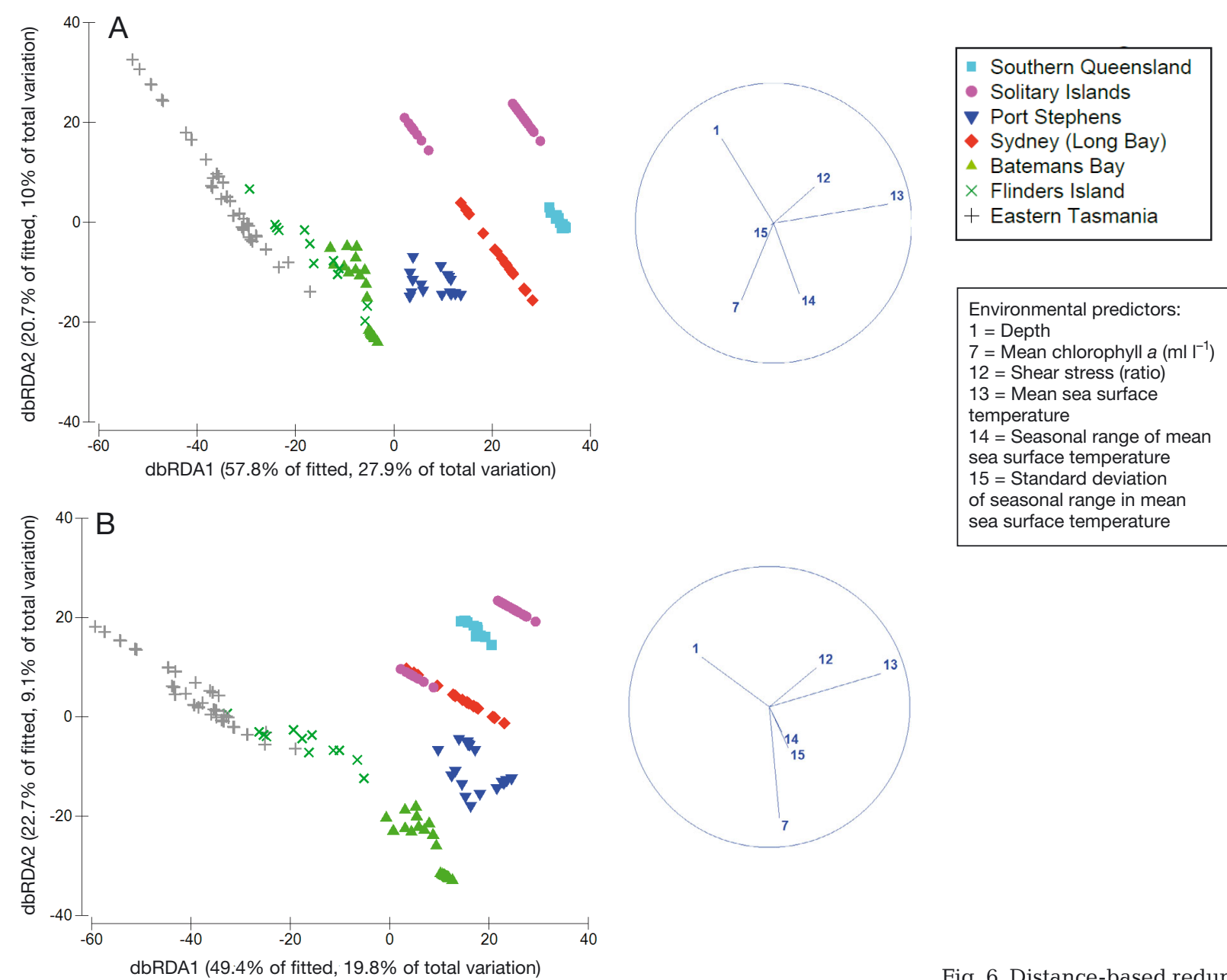

7 = Mean chlorophyll $a\left(\mathrm{ml} \mathrm{l}^{-1}\right)$

$12=$ Shear stress (ratio)

sea surface temperature

of seasonal range in mean

surface temperature

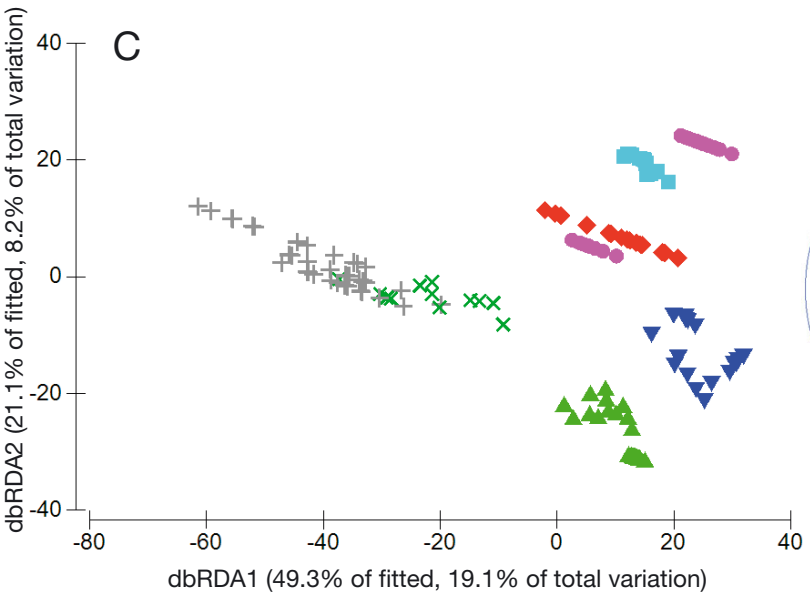

Fig. 6. Distance-based redundancy analysis (dbRDA) ordination relating dissimilarities in sessile benthic invertebrate composition (based on Bray-Curtis similarity, square-root transformation), with environmental predictors identified as the 'BEST solution' capturing the observed variability in the distance-based linear model (DISTLM) analysis. Vector overlay represents the projection of each predictor onto the first 2 axes of the dbRDA, when using (A) CATAMI, (B) Group and (C) Morphotype benthic invertebrate classifications (see 'Methods' for details of each classification)

\section{DISCUSSION}

Our study is the first to quantify large-scale latitudinal variation in sessile invertebrate community composition on deep reefs $(>30 \mathrm{~m}$ ) on the continental shelf in eastern Australia. Encompassing $\sim 1800 \mathrm{~km}$ of coastline and a latitudinal range of $\sim 16^{\circ}$, our study covers a much greater area and range of habitats than previous studies in the region (Roberts \& Davis 1996, Roberts et al. 2006, Edgar et al. 2010) and provides a first quantitative baseline about the distribution and community structure of temperate sessile benthic invertebrates on reefs beyond workable diving depths on the southeastern seaboard of Australia. 


\section{Spatial variation in deep-reef sessile invertebrate community structure in eastern Australia}

Major changes in deep benthic invertebrate community composition off eastern Australia occur gradually over a large-scale (>1000 km) latitudinal gradient from sub-tropical to cool temperate waters. From southern Queensland to southeastern Tasmania, relatively distinct sub-tropical $\left(\sim 27-30^{\circ} \mathrm{S}\right)$, warm temperate $\left(\sim 32-36^{\circ} \mathrm{S}\right)$ and cool temperate $\left(40-43^{\circ} \mathrm{S}\right)$ community types were evident and can be characterised by the dominance of region-specific benthic invertebrate types. The pink and white rigid (gorgonian) sea fans and brown octocoral which characterised the sub-tropical reefs (southern Queensland and Solitary Islands) were restricted to these regions, and are known to occur mostly in tropical and subtropical environments (Edgar 2012). High cover of the white, hard, fenestrate bryozoan and purple solitary ascidian is typical of the warm temperate assemblages observed at Port Stephens, Sydney (Long Bay) and Batemans Bay in New South Wales, while various morphospecies of erect (branching, laminar and palmate), massive and cup sponges, soft bryozoans and soft gorgonians dominated the cool temperate communities in the Tasmanian regions.

Similar large-scale spatial patterns have been observed in benthic communities on the western seaboard of Australia across a latitudinal gradient from sub-tropical to temperate areas $\left(28.5-33.5^{\circ} \mathrm{S}\right.$; Smale et al. 2010, Williams et al. 2010, Fromont et al. 2012). Smale et al. (2010) reported that 'sub-tropical' benthic assemblages in the northernmost locations were dominated by hard corals, contrasted with 'temperate' reefs characterised by increasing percentage cover of sponges and bryozoans at depths $>30 \mathrm{~m}$.

\section{Physical factors associated with large-scale variation in community structure}

This variability in deep reef community composition at large scales correlates well with large-scale ocean features, in particular the north-south gradient in mean SST and mean surface primary production (Fig. 6). In other studies in Western Australia (Smale et al. 2010, Williams et al. 2010), coastal Antarctica (Cummings et al. 2006, 2010, Schiaparelli et al. 2014) and California, USA (Schoch et al. 2006), large-scale (100-1000 km) variability in deep (>100 m) (Cummings et al. 2010, Williams et al. 2010, Schiaparelli et al. 2014) and shallow (<30 m) (Cum- mings et al. 2006, Schoch et al. 2006) benthic communities were also correlated with gradients in ocean temperature and latitude (Schoch et al. 2006, Smale et al. 2010, Williams et al. 2010), as well as proximity to large- and meso-scale ocean processes such as currents and upwelling (Schoch et al. 2006, Smale et al. 2010), and exposure to disturbances (i.e. benthic scouring, wave dynamics) (Cummings et al. 2006, 2010, Schoch et al. 2006). As mean SST is predicted to increase across southeastern Australia by at least $1^{\circ} \mathrm{C}$ by 2060 (Oliver \& Holbrook 2014), ongoing and future climate-driven changes in these deep reef communities are likely. Continued systematic spatial and temporal monitoring by the IMOS AUV programme will be essential to quantify these changes, and for other future deep benthic ecosystem research in southeastern Australia.

\section{Baseline to monitor and predict future climate- driven changes}

While the potential impacts of climate-driven ocean changes are well documented for kelp (Wernberg et al. 2010, Johnson et al. 2011) and coral species (Spillman et al. 2013), there remains uncertainty about how future climate change is likely to influence the distribution of non-coral benthic sessile invertebrates (Przeslawski et al. 2008, Kelmo et al. 2013). Recent studies have shown inconsistent results, with some indicating that under warmer future climate conditions, deep sessile organisms, particularly sponges, may benefit (e.g. colonise and establish on newly available reef space due to declines in other habitat-forming species, such as corals; Norström et al. 2009, González-Rivero et al. 2011, Kelmo et al. 2013), while others suggest negative impacts (e.g. mass mortalities due to extreme climatic events such as marine heat waves; Cerrano et al. 2000, Perez et al. 2000, Garrabou et al. 2009, Cebrian et al. 2011). Overall, current capacity to mechanistically explain the present distribution of non-coral deep reef sessile invertebrates and predict their responses to ocean changes is limited by poor understanding of their physiology and ecology (e.g. larval ecology and dispersal capacities) (Wörheide et al. 2005, Maldonado 2006, Przeslawski et al. 2008).

In this context, our study provides an important benchmark to monitor and predict future changes in deep reef communities in southeastern Australia, which is a global hotspot for ocean warming (Hobday \& Pecl 2014). Regular monitoring of the deep reef communities will be essential to detect climate- 
driven range shifts, which is one of the most commonly described responses of marine taxa to climate change. Indeed, they have been documented for dozens of marine species in southeastern Australia (Ling et al. 2009, Pitt et al. 2010, Johnson et al. 2011, Robinson et al. 2015), although the majority of studies on marine range shifts to date are mainly focussed on fishes and mobile invertebrate taxa (e.g. Pinsky et al. 2013) tropical (e.g. corals; Precht \& Aronson 2004) or shallow temperate habitat-formers (e.g. Ecklonia radiata seaweed beds; Precht \& Aronson 2004, Wernberg et al. 2010). Future monitoring of deep reef communities in southeastern Australia may provide novel insights on the ability of deeper reef habitatformers to re-distribute under future climates, thus providing a useful benchmark to detect (Bates et al. 2014) both southwards range extension of subtropical benthic organisms (e.g. subtropical obligate sea fans and octocorals), or contraction of the northern boundary distribution of cold temperate invertebrate species, morphotypes or functional groups (e.g. large erect and massive sponges). Statistical modelling of the distribution of individual functional (CATAMI) groups or morphotypes based on the kind of information established in this study should provide valuable insight into potential redistribution of these organisms under future climate projections and help identify the most sensitive indicators for monitoring. Characterising shifts in the distribution of individual invertebrate species from imagery is difficult and only possible for relatively few organisms. However, where species-level identification is possible, AUV monitoring at this level should be favoured. Our study offers an assessment of one of the solutions to this current limitation, by the means of the CATAMI functional group classification. Our results indicate that particular functional groups are characteristic to certain regions in southeastern Australia; therefore, we consider it valid to monitor for range shifts and the redistribution of these organisms at a functional group level.

At the community level, regular monitoring will be crucial to understanding both the direct and indirect community effects of individual morphospecies range shifts, including climate-driven 'invasions' of temperate assemblages by tropical taxa (e.g. tropical grazing fishes; Vergés et al. 2014, Bennett et al. 2015). However, current examples of rapid species range shifts leading to major reorganisations in marine ecosystems are largely restricted to pelagic or shallow benthic communities (Johnson et al. 2011). For example, in eastern Tasmania, the climate-driven invasion of the long-spined sea urchin Centro- stephanus rodgersii has precipitated dramatic (and hard-to-reverse) community shifts from productive kelp beds to sea urchin 'barrens' devoid of macroalgae following destructive grazing by the urchins (Ling et al. 2009, Johnson et al. 2011, Marzloff et al. 2016a). Southward range shift of tropical grazing fishes has induced similar ecological effects in establishing and maintaining macroalgal-free reefs in warm temperate waters (Vergés et al. 2014, Bennett et al. 2015, Marzloff et al. 2016b). Shifts in benthic sessile invertebrate communities under ongoing ocean changes can similarly lead to the dominance of a single invertebrate type (as partially reviewed by Przeslawski et al. 2008), such as sponges (Rutzler 2002), ascidians (Stachowicz et al. 2002, Agius 2007) or bryozoans (Saunders \& Metaxas 2007). The effects of climate-driven shifts in benthic invertebrate communities, in particular the loss of species and functional diversity, may have broad ecological implications given that these sessile invertebrates provide essential services (e.g. food and habitat) to benthic species (Fromont et al. 2006, Bell 2007, Schlacher et al. 2010, Schönberg \& Fromont 2012) and ecosystem functioning (e.g. nutrient recycling; de Goeij et al. 2013).

\section{Physical factors associated with small-scale variation in community structure}

In our study, local-scale variability in benthic community structure related largely to differences in depth (Fig. 6; Tables 3-5). Depth gradients in benthic sessile invertebrate assemblages have been a consistent pattern to emerge from cross-shelf studies in Western Australia (Fromont et al. 2006, Williams et al. 2010, Schönberg \& Fromont 2012), the Great Australian Bight (Ward et al. 2006), northern Queensland (Wilkinson \& Cheshire 1989, Hooper \& Kennedy 2002, Bridge et al. 2011) and off the coast of Sydney, New South Wales (Roberts \& Davis 1996, Roberts et al. 2006). However, depth acts as a robust surrogate for several other environmental variables, such as temperature, light availability, organic matter, slope or dissolved oxygen (Bridge et al. 2011, Compton et al. 2013, Pilditch et al. 2015), so identifying the mechanism behind the pattern is non-trivial. If the depth range is large, such as across the continental margin in Western Australia (depth 100-1100 m) where distinct benthic communities occur coincident with persistent depth-stratified variation in temperature and oxygen created by prevailing ocean currents and different water masses along the shelf and slope 
(Williams et al. 2010), potential mechanisms can be identified. However, in our study, the depth ranges surveyed at each site are relatively small (mostly between 30 and $50 \mathrm{~m}$; see Table $\mathrm{S} 1$ in the Supplement at www.int-res.com/articles/suppl/m565p035_ supp.pdf), limiting ecological interpretation. Moreover, our ability to identify drivers of fine-scale variability in benthic community structure is limited both by the lack of high-resolution information of local habitat features (e.g. reef complexity and patchiness) and the coarse spatial resolution of most environmental data (e.g. latitude and longitude $0.1^{\circ}$ grid for SST).

Both southern Queensland and Long Bay (Sydney) regions to some extent constitute outliers in our analyses, as sampled communities in these regions were overall depauperate of fauna and highly heterogeneous spatially. We could not clearly relate these local trends with the environmental variables considered in our study. However, in southern Queensland, the coastal environment is driven by the presence of a local upwelling, which allows for the northernmost temperate kelp beds to thrive around Henderson Island at the survey site (described by Marzinelli et al. 2015). The reduced cover of fauna at Long Bay's surveyed sites might be related to the proximity of Long Bay to the heavily populated urban area of Sydney, and the bay itself having a history of significant sewerage pollution and concomitant effects on water quality (Sydney Water 2007).

\section{Sensitivity to seafloor image selection and annotation scheme}

Both the broad-scale latitudinal gradient in benthic community composition and significant differences between regions were consistent across all 3 seafloor biota image-based classification schemes. The broad-level CATAMI classification of benthic biota (Althaus et al. 2015) performs as well as more timeconsuming, higher-resolution classifications at characterising large-scale changes in community structure. Thus, the benthic classification scheme for underwater imagery annotation recently set by CATAMI appears to provide a reliable and standardised approach, and is likely to prove useful to characterise differences in community composition across benthic ecosystems worldwide. While the CATAMI scheme does not comprehensively capture detailed community composition and variability, this study shows that targeted scoring of a subset of preselected conspicuous and easy-to-identify inverte- brate groups (see Table S2 in the Supplement) can provide a valid and time-efficient alternative to other image scoring strategies to describe changes in community structure across large scales (100-1000 km). However, while the CATAMI image annotation scheme proves effective at characterising large-scale changes in community structure, its coarse classification may limit its utility to monitor local-scale changes in community composition or changes in the abundance and/or distribution of specific morphotypes of interest.

\section{Limitations and caveats}

While the present study identifies broad variation in composition of the deep subtidal benthic invertebrate communities along Australia's east coast, for several reasons total variability in diversity and community structure is under-sampled. First, the spatial coverage was limited due to the sparseness of the AUV national reference stations (e.g. there are no sites in Victoria, the southeastern corner state of mainland Australia). Sufficient data to enable robust analysis of temporal variability in community composition are not yet available, and for this study only a small proportion of the available AUV images were quantified. Therefore, we did not investigate temporal variability in the composition of surveyed communities; however, the reduced changes observed in deep reef community composition in southeastern Australia since the onset of the AUV monitoring programme in 2007 suggests that the large-scale patterns described in this paper are robust to year-toyear variability (N. R. Perkins et al. unpubl.). Finally, our pre-selection of particular subsets of sessile invertebrates (i.e. larger, colourful and distinctive morphotypes) for scoring means that our communitybased analyses are not necessarily representative of the community as a whole.

\section{Conclusions}

Our study characterises latitudinal gradients in the composition and distribution of benthic sessile invertebrate communities on deep ( 30-90 m) continental shelf reefs in southeastern Australia, providing an essential benchmark to detect the effects of climate change on deeper reef communities in an area identified as a global hotspot for climate-driven ocean change. Ongoing and extended monitoring, including of region-specific invertebrate types that can 
serve as useful ecological indicators, will be key to understanding and predicting the responses of these deep reef communities to ongoing and future ocean change. At a methodological level, our approach, including the use of the CATAMI scheme for the classification of benthic biota, demonstrates general applicability for large-scale study and monitoring of deep reef communities.

Acknowledgements. We thank the Integrated Marine Observing System (IMOS) for ongoing long-term support to the nation-wide AUV monitoring programme. We also acknowledge the support of DPI NSW, IMAS and the NERP Marine biodiversity hub, a collaborative partnership supported through the Australian Government's National Environmental Science Program, for facilitating some of the AUV deployments that provided the benthic data used in our analyses. Special thanks to Prof. Stefan Williams and the Australian Centre for Field Robotics (ACFR) at the University of Sydney for facilitating access and scoring of AUV imagery. M.P.M. and the overall research project were funded by the Australian Research Council 2011 Super Science Fellowship scheme (project: FS110200029).

\section{LITERATURE CITED}

Agius B (2007) Spatial and temporal effects of pre-seeding plates with invasive ascidians: growth, recruitment and community composition. J Exp Mar Biol Ecol 342:30-39

Althaus F, Hill N, Ferrari R, Edwards L and others (2015) A standardised vocabulary for identifying benthic biota and substrata from underwater imagery: the CATAMI classification scheme. PLOS ONE 10:e0141039

Anderson MJ, Willis TF (2003) Canonical analysis of principal coordinates: a useful method of constrained ordination for ecology. Ecology 84:511-525

Anderson MJ, Gorley RN, Clarke KR (2008). PERMANOVA+ for PRIMER: guide to software and statistical methods. PRIMER-E, Plymouth

Barnes RA, Eplee RE, Schmidt GM, Patt FS, McClain CR (2001) Calibration of SeaWiFS. I. Direct techniques. Appl Opt 40:6682-6700

Bates AE, Pecl GT, Frusher S, Hobday AJ and others (2014) Defining and observing stages of climate mediated range shifts in marine systems. Glob Environ Change 26:27-38

Bell JJ (2007) Contrasting patterns of species and functional composition of coral reef sponge assemblages. Mar Ecol Prog Ser 339:73-81

* Bennett S, Wernberg T, Harvey ES, Santana-Garcon J, Saunders BJ (2015) Tropical herbivores provide resilience to a climate-mediated phase shift on temperate reefs. Ecol Lett 18:714-723

Bridge TCL, Done TJ, Friedman A, Beaman RJ, Williams SB, Pizarro O, Webster JM (2011) Variability in mesophotic coral reef communities along the Great Barrier Reef, Australia. Mar Ecol Prog Ser 428:63-75

* Bridge T, Beaman R, Done T, Webster J (2012) Predicting the location and spatial extent of submerged coral reef habitat in the Great Barrier Reef World Heritage Area, Australia. PLOS ONE 7:e48203

Cebrian E, Uriz MJ, Garrabou J, Ballesteros E (2011) Sponge mass mortalities in a warming Mediterranean Sea: Are cyanobacteria-harboring species worse off? PLOS ONE 6:e20211

*Cerrano C, Bavestrello G, Bianchi CN, Cattaneo-Vietti R and others (2000) A catastrophic mass-mortality episode of gorgonians and other organisms in the Ligurian Sea (North-western Mediterranean), summer 1999. Ecol Lett 3:284-293

Christie H, Norderhaug KM, Fredriksen S (2009) Macrophytes as habitat for fauna. Mar Ecol Prog Ser 396: 221-233

Clarke KR, Somerfield PF, Airoldi L, Warwick RM (2006) Exploring interactions by second-stage community analyses. J Exp Mar Biol Ecol 338:179-192

Compton TJ, Bowden DA, Pitcher CR, Hewitt JE, Ellis N (2013) Biophysical patterns in benthic assemblage composition across contrasting continental margins off New Zealand. J Biogeogr 40:75-89

Cummings V, Thrush S, Norkko A, Andrew N, Hewitt J, Funnell G, Schwarz AM (2006) Accounting for local scale variability in benthos: implications for future assessments of latitudinal trends in the coastal Ross Sea. Antarct Sci 18:633-644

* Cummings VJ, Thrush S, Chiantore M, Hewitt J, CattaneoVietti R (2010) Macrobenthic communities of the northwestern Ross Sea shelf: links to depth, sediment characteristics and latitude. Antarct Sci 22:793-804

* de Goeij JM, Van Oevelen D, Vermeij MJA, Osinga R, Middleburg JJ, de Goeij AFPM, Admiraal W (2013) Surviving in a marine desert: the sponge loop retains resources with coral reefs. Science 342:108-110

Wunn JR, Ridgway KR (2002) Mapping ocean properties in regions of complex topography. Deep-Sea Res I 49:591-604

Edgar G (2012) Australian marine life: the plants and animals of temperate waters. Reed New Holland, Chatswood

Edgar GJ, Last PR, Barrett NS, Gowlett-Holmes K, Driessen M, Mooney P (2010) Conservation of natural wilderness values in the Port Davey marine and estuarine protected area, south-western Tasmania. Aquat Conserv 20:297-311

Eplee RE, Robinson WD, Bailey SW, Clark DK and others (2001) Calibration of SeaWiFS. II. Vicarious techniques. Appl Opt 40:6701-6718

FFromont J, Vanderklift MA, Kendrick GA (2006) Marine sponges of the Dampier Archipelago, Western Australia: patterns of species distributions, abundance and diversity. Biodivers Conserv 15:3731-3750

Fromont J, Althaus F, McEnnulty FR, Williams A, Salotti M, Gomez O, Gowlett-Holmes K (2012) Living on the edge: the sponge fauna of Australia's southwestern and northwestern deep continental margin. Hydrobiologia 687: $127-142$

Garrabou J, Coma R, Bensoussan N, Bally M and others (2009) Mass mortality in Northwestern Mediterranean rocky benthic communities: effects of the 2003 heat wave. Glob Change Biol 15:1090-1103

*González-Rivero M, Yakob L, Mumby PJ (2011) The role of sponge competition on coral reef alternative steady states. Ecol Model 222:1847-1853

* Hemer M (2006) The magnitude and frequency of combined flow bed shear stress as a measure of exposure on the Australian continental shelf. Cont Shelf Res 26: 1258-1280

*Hobday AJ, Pecl GT (2014) Identification of global marine hotspots: sentinels for change and vanguards for adaptation action. Rev Fish Biol Fish 24:415-425 
Hooper JNA, Kennedy JA (2002) Small-scale patterns of sponge biodiversity (Porifera) from the Sunshine Coast reefs, Eastern Australia. Invertebr Syst 16:637-653

Huang Z (2013) Bathymetry derived topographic relief grid. Geoscience Australia, Canberra

Johnson CR, Banks SC, Barrett NS, Cazassus F and others (2011) Climate change cascades: shifts in oceanography, species' ranges and subtidal marine community dynamics in eastern Tasmania. J Exp Mar Biol Ecol 400:17-32

Kelmo F, Bell JJ, Attrill MJ (2013) Tolerance of sponge assemblages to temperature anomalies: resilience and proliferation of sponges following the 1997-8 El-Nino southern oscillation. PLOS ONE 8:e76441

*Legendre P, Anderson MJ (1999) Distance-based redundancy analysis: testing multispecies responses in multifactorial ecological experiments. Ecol Monogr 69:1-24

Ling SD, Johnson CR, Frusher SD, Ridgway KR (2009) Overfishing reduces resilience of kelp beds to climate-driven catastrophic phase shift. Proc Natl Acad Sci USA 106: 22341-22345

* Ling SD, Mahon I, Marzloff MP, Pizarro O, Johnson CR, Williams SB (2016) Stereo imaging AUV detects trends in sea urchin abundance on deep overgrazed reefs. Limnol Oceanogr Methods 14:293-304

Long BG, Bode L, Pitcher R (1997) Seabed current stress as a predictor of the distribution and abundance of epibenthos in Torres Strait. CSRIO Marine Research Report MR-GIS 97/6, Hobart

Maldonado M (2006) The ecology of the sponge larva. Can J Zool 84:175-194

Marzinelli EM, Williams SB, Babcock RC, Barrett NS and others (2015) Large-scale geographic variation in distribution and abundance of Australian deep-water kelp forests. PLOS ONE 10:e0118390

Marzloff MP, Johnson CR, Little LR, Soulié JC, Ling SD, Frusher SD (2013) Sensitivity analysis and patternoriented validation of TRITON, a model with alternative community states: insights on temperate rocky reefs dynamics. Ecol Model 258:16-32

Marzloff MP, Little LR, Johnson CR (2016a) Building resilience against climate-driven shifts in a temperate reef system: staying away from context-dependent ecological thresholds. Ecosystems 19:1-15

* Marzloff MP, Melbourne-Thomas J, Hamon KG, Hoshino E, Jennings S, van Putten I, Pecl GT (2016b) Modelling marine community responses to climate-driven species redistribution to guide monitoring and adaptive ecosystem-based management. Glob Change Biol 22: 2462-2474

Norström AV, Nyström M, Lokrantz J, Folke C (2009) Alternative states on coral reefs: beyond coral-macroalgal phase shifts. Mar Ecol Prog Ser 376:295-306

Oliver ECJ, Holbrook NJ (2014) A statistical method for improving continental shelf and nearshore marine climate predictions. J Atmos Ocean Technol 31:216-232

Perez T, Garrabou J, Sartoretto S, Harmelin JG, Francour P, Vacelet J (2000) Mass mortality of marine invertebrates: an unprecedented event in the Northwestern Mediterranean. C R Acad Sci III 323:853-865

Pilditch CA, Leduc D, Nodder SD, Probert PK, Bowden DA (2015) Spatial patterns and environmental drivers of benthic infaunal community structure and ecosystem function on the New Zealand continental margin. N Z J Mar Freshw Res 49:224-246
Pinsky ML, Worm B, Fogarty MJ, Sarmiento JL, Levin SA (2013) Marine taxa track local climate velocities. Science 341:1239-1242

Pitt NR, Poloczanska ES, Hobday AJ (2010) Climate-driven range changes in Tasmanian intertidal fauna. Mar Freshw Res 61:963-970

* Pizarro O, Williams SB, Jakuba MV, Johnson-Roberson M and others (2013) Benthic monitoring with robotic platforms - the experience of Australia. Proc IEEE International Underwater Technology Symposium (UT), 5-8 Mar, Tokyo. http://ieeexplore.ieee.org/stamp/stamp.jsp? $\mathrm{tp}=$ \&arnumber $=6519909$ \&isnumber $=6519807$

* Precht WF, Aronson RB (2004) Climate flickers and range shifts of reef corals. Front Ecol Environ 2:307-314

* Przeslawski R, Ahyong S, Byrne M, Wörheide G, Hutchings P (2008) Beyond corals and fish: the effects of climate change on noncoral benthic invertebrates of tropical reefs. Glob Change Biol 14:2773-2795

Ridgway KR, Dunn JR, Wilkin JL (2002) Ocean interpolation by four dimensional weighted least squares-application to the waters around Australasia. J Atmos Ocean Technol 19:1357-1375

Koberts DE, Davis AR (1996) Patterns in sponge (Porifera) assemblages on temperate coastal reefs off Sydney, Australia. Mar Freshw Res 47:897-906

Roberts DE, Cummins SP, Davis AR, Chapman MG (2006) Structure and dynamics of sponge-dominated assemblages on exposed and sheltered temperate reefs. Mar Ecol Prog Ser 321:19-30

Robinson LM, Gledhill DC, Moltschaniwskyj NA, Hobday AJ and others (2015) Rapid assessment of an ocean warming hotspot reveals "high" confidence in potential species' range extensions. Glob Environ Change 31:28-37

Rutzler K (2002) Impact of crustose clionid sponges on Caribbean reef corals. Acta Geol Hisp 37:61-72

* Saunders M, Metaxas A (2007) Temperature explains settlement patterns of the introduced bryozoan Membranipora membranacea in Nova Scotia, Canada. Mar Ecol Prog Ser 344:95-106

* Schiaparelli S, Ghiglione C, Alvaro C, Griffiths HJ, Linse K (2014) Diversity, abundance and composition in macrofaunal molluscs from the Ross Sea (Antarctica): results of fine-mesh sampling along a latitudinal gradient. Polar Biol 37:859-877

* Schlacher TA, Williams A, Althaus F, Schlacher-Hoenlinger MA (2010) High-resolution seabed imagery as a tool for biodiversity conservation planning on continental margins. Mar Ecol 31:200-221

* Schoch GC, Menge BA, Allison G, Kavanaugh M, Thompson SA, Wood SA (2006) Fifteen degrees of separation: latitudinal gradients of rocky intertidal biota along the California Current. Limnol Oceanogr 51:2564-2585

* Schönberg CHL, Fromont J (2012) Sponge gardens of Ningaloo Reef (Carnarvon Shelf, Western Australia) are biodiversity hotspots. Hydrobiologia 687:143-161

Smale DA, Wernberg T (2009) Satellite-derived SST data as a proxy for water temperature in nearshore benthic ecology. Mar Ecol Prog Ser 387:27-37

Smale DA, Wernberg T (2013) Extreme climatic event drives range contraction of a habitat-forming species. Proc R Soc Lond B Biol Sci 280:20122829

Smale DA, Kendrick GA, Waddington KI, Van Niel KP, Meeuwig JJ, Harvey ES (2010) Benthic assemblage composition on subtidal reefs along a latitudinal gradient in Western Australia. Estuar Coast Shelf Sci 86:83-92 
Spillman CM, Alves O, Hudson DA (2013) Predicting thermal stress for coral bleaching in the Great Barrier Reef using a coupled ocean-atmosphere seasonal forecast model. Int J Climatol 33:1001-1014

Stachowicz JJ, Terwin JR, Whitlatch RB, Osman RW (2002) Linking climate change and biological invasions: Ocean warming facilitates nonindigenous species invasions. Proc Natl Acad Sci USA 99:15497-15500

Sydney Water (2007) Sydney's deepwater ocean outfalls longterm environmental performance - Ocean Outfall Annual Report. https://www.sydneywater.com.au/Publications/ Reports/AnnualReport/2007/downloads/OceanOutfall AnnualReport.pdf

Tegner MJ, Dayton PK (2000) Ecosystem effects of fishing in kelp forest communities. ICES J Mar Sci 57:579-589

Vergés A, Steinberg PD, Hay ME, Poore AGB and others (2014) The tropicalization of temperate marine ecosystems: climate mediated changes in herbivory and community phase shifts. Proc R Soc Lond B Biol Sci 281: 20140846

Ward TM, Sorokin SJ, Currie DR, Rogers PJ, McLeay LJ (2006) Epifaunal assemblages of the eastern Great Australian Bight: effectiveness of a benthic protection zone

Editorial responsibility: Charles Birkeland,

Honolulu, Hawaii, USA in representing regional biodiversity. Cont Shelf Res 26: 25-40

* Wernberg T, Thomsen MS, Tuya F, Kendrick GA, Staehr PA, Toohey BD (2010) Decreasing resilience of kelp beds along a latitudinal temperature gradient: potential implications for a warmer future. Ecol Lett 13:685-694

Wilkinson CR, Cheshire AC (1989) Patterns in the distribution of sponge populations across the central Great Barrier Reef. Coral Reefs 8:127-134

Williams A, Althaus F, Dunstan PK, Poore GCB, Bax NJ, Kloser RJ, McEnnulty FR (2010) Scales of habitat heterogeneity and megabenthos biodiversity on an extensive Australian continental margin (100-1100 m depths). Mar Ecol 31:222-236

Williams SB, Pizarro OR, Jakuba MV, Johnson CR and others (2012) Monitoring of benthic reference sites using an autonomous underwater vehicle. IEEE Robot Autom Mag 19:73-84

Wörheide G, Solé-Cava AM, Hooper JNA (2005) Biodiversity, molecular ecology and phylogeography of marine sponges: patterns, implications and outlooks. Integr Comp Biol 45:377-385

Submitted: March 8, 2016; Accepted: November 15, 2016 Proofs received from author(s): February 1, 2017 